ISSN 1112-9867

http://www.jfas.info

\title{
MESH MATERIAL FEASIBILITY TESTS FOR MAXIMUM WATER COLLECTION \\ BY USING WHITE PE PLASTIC SHEET, BLACK POLYOLEFIN MESHES AND HDPE GREEN MESH
}

N. H. M. Isa ${ }^{1}$, N. R. Awang ${ }^{1}$, M. I. Ahmad ${ }^{2}$, M. S. M. Rasat ${ }^{2}$, M. F. M. Amin ${ }^{1, *}$ and Z. I. $\operatorname{Rizman}^{3}$

${ }^{1}$ Faculty of Earth Science, Universiti Malaysia Kelantan, Jeli, Kelantan, Malaysia

${ }^{2}$ Faculty of Bio-Engineering and Technology, Universiti Malaysia Kelantan, Jeli, Kelantan, Malaysia

${ }^{3}$ Faculty of Electrical Engineering, UniversitiTeknologi MARA, 23000 Dungun, Terengganu, Malaysia

Published online: 10 September 2017

\begin{abstract}
Multiple linear regression analysis prove that meteorological effects and material properties of mesh can affect the volume of water collected. To compare the feasibility of material tests for maximum water collection, One-way ANOVA analysis were used to obtain comparison data. This study aimed to find an alternative way to reduce water scarcity issues in highland area. The sources of surface water and sources of groundwater are almost none. The material (mesh) that used onto the atmospheric water harvester implements an important role in maximizing water collection volume. A potable sturdy frame to hold the mesh material tests were developed and the water collected will be directly flow into a water container and the volume of water collected will be recorded.
\end{abstract}

Author Correspondence, e-mail: mohamadfaiz@umk.edu.my

doi: http://dx.doi.org/10.4314/jfas.v9i3s.68 
This study aimed to select the most applicable mesh material that can be add up on to atmospheric water harvester to maximize volume of water collection.

Keywords: atmospheric water; material tests; meshes; maximum water collection.

\section{INTRODUCTION}

Atmospheric water are consists of three different states which are fog, water precipitation (dew) and rainfall. In this study, fog is one part of the important hydrology cycle of coastal, high-altitude and forested regions that commonly overlooked by the world community [2] while dew is known as water precipitation that formed on the plants surfaces that plays crucial roles as water supply in desert area [4]. As for rain, it is water droplets that condense through water vapors condensation process at the atmosphere after the water vapor evaporates from Earth surfaces. As it accumulates until it reach optimum weight before it is precipitate into rainfall [7].

Recent research study shows atmospheric water harvesting can be an alternative source that can reduce water scarcity issue among people in semi-arid, highland, coastal and tropical regions [2]. It presents atmospheric water harvester as viable alternatives to existing water supply systems. Water scarcity issues become more serious when the populations increase over the years. This matter ultimately contributes to the occurrence of water scarcity [3].

Traditionally, fog harvesting uses a simple method where the use of mesh that framed on a sturdy frames and expose to the air. When the fog passes through the mesh, water vapor deposited and becomes dew which will accumulate and run down to water collector or drainage container [6]. Throughout the fog water harvesting studies, there are new models for fog water collection, an impaction model and an efficiency model that had been developed to describe the process that occur on a [5]. Fog water harvesting implies a passive, low cost and maintenance system to supply fresh drinking water for communities that lived in foggy area. It is also useful when the water sources are scarce [2].

In Malaysia, tropical climate did not affected badly by the water scarcity issue compare to arid climate. However, for highland area, clean water supply is limited because there is less availability of surface water. Therefore, supplying water for people in tropical regions has 
gained high importance in the recent days. The methods of collecting water by harvesting from atmospheric or air humidity could be very beneficial. In [10] pointed out the importance of alternative water supplies such as atmospheric water harvesting in food security. To continue the research on atmospheric water harvesting, research on mesh material's feasibility on maximizing volume of water collection was carried out.

\section{METHODOLOGY}

The experiment was conducted at vacant area nearby Environmental Research Laboratory of Universiti Malaysia Kelantan, Jeli Campus. The experiment was carried out for 60 days continuously and the monitoring data will be taken between 7.30 am to $7.45 \mathrm{am}$. Water precipitation on the material test panels (white PE plastic sheet, Black Polyolefin Mesh and HDPE Green Mesh) volume of water collected will be recorded in the morning. The meteorological data can be obtained from the Malaysia Meteorological Department's website.

\subsection{Preparation of Sturdy Frame for Material Tests}

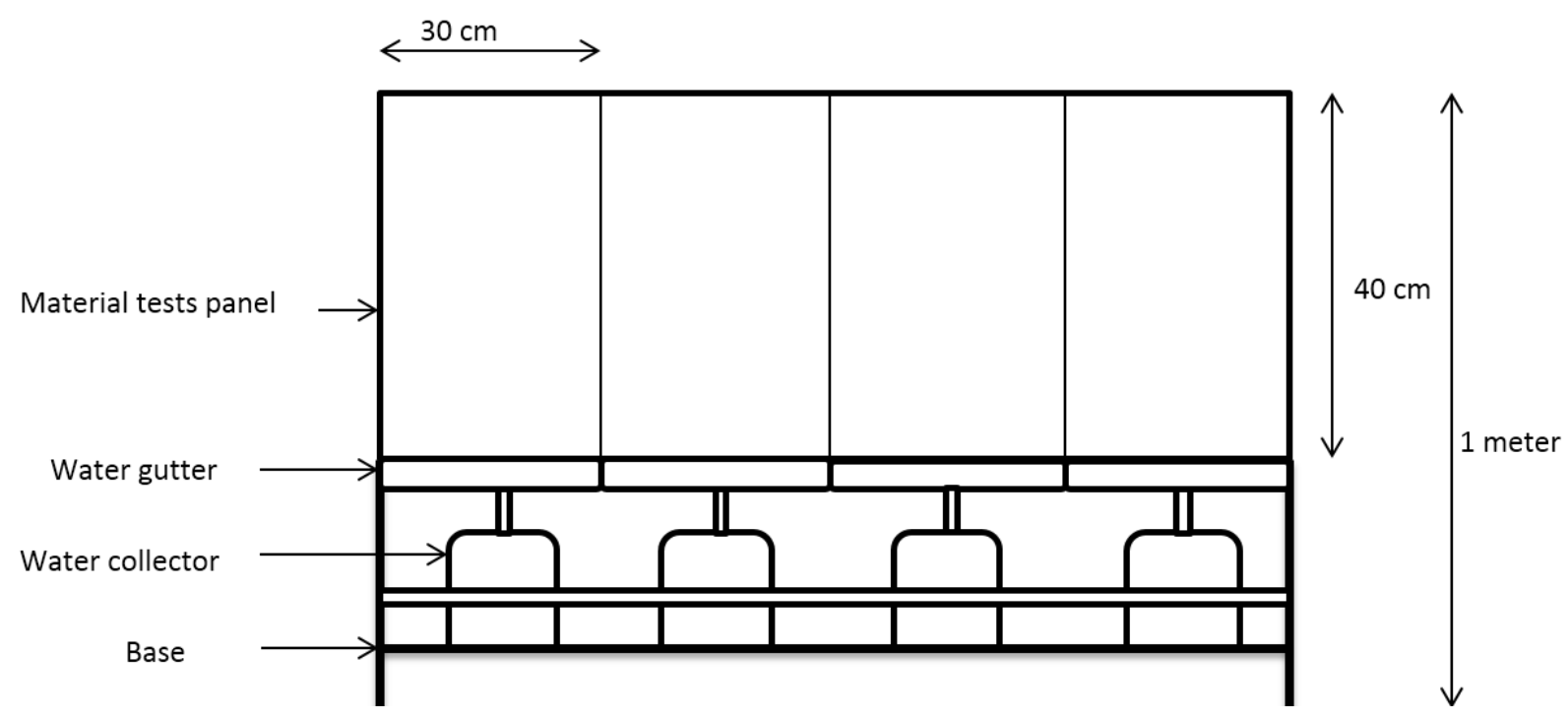

Fig.1. Material tested sturdy frame

1 meter height of sturdy frame with 2 meter width was developed by using stainless steel.

Four panel segments for material tests were divided with 1 feet width each. The segments were setup about 0.5 meters above the ground. Each segment was connected with water gutter that will collect deposited water droplets which flows into the water container. Material test was attached to the panel segments by using cable ties. 


\subsection{Characterization of Material Test}

Material tests should have textural surfaces and chemical features on their surfaces to harvest the fog. The material tests should have the surface wettability characteristics (hydrophobicity and hydrophilicity) [9] length scale (width and length of the mesh) and weave density on the fog-harvesting capability of woven meshes. For an ideal fog-collecting surface, liquid droplets converted toward the mesh and deposited on the surface will be drained quickly by gravity into the collecting gutter without the loss by re-entrainment to the airflow, thus refreshing the base mesh surface for the capture of new fog droplets [8].

Therefore, hydrophilicity of mesh surfaces is important as it attracts fog droplets to deposit on the mesh surfaces. Meanwhile, hydrophobicity of a surfaces will helps in providing water deposited flow into the water collector easily. The mesh weave patterns surfaces cannot be too sparse or too close because the water deposited will easily loss through the air because of the wind. Thus, the mesh density also plays an important role to withstand the wind blow or storms [1].

\subsection{Statistical Analysis}

All analysis results were subjected to statistical analysis to determine mean and standard deviation using the latest statistical software (SPSS software). To relate the primary data collection with secondary data collection, multiple linear linear regression analysis will be used to correlate the interrelationship between type of mesh materials and meteorological data. Meamwhile, to compare the feasibility of mesh material tested, analysis of variance (ANOVA) will be used.

\section{RESULTS AND DISCUSSION}

\subsection{Descriptive Analysis on Volume of Water Collected $\left(\mathrm{cm}^{3}\right)$ in 60 days}


Table 1. Volume of water collected for each material test

\begin{tabular}{cc}
\hline Mesh Material Tests & Volume of Water Collected in 60 days \\
\hline White PE Plastic sheet & 33.3 \\
Black Polyolefin Mesh (2mm) & 34.6 \\
Black Polyolefin Mesh (1mm) & 49.7 \\
HDPE Green Mesh & 43.3 \\
\hline
\end{tabular}

Based on Table 1, the highest volume of water collected in 60 days is (Black Polyolefin Mesh $1 \mathrm{~mm}$ width range $=49.7 \mathrm{~cm}^{3}$ ). Black Polyolefin Mesh with weave width $1 \mathrm{~mm}$ is feasible in capturing rain water, drizzle and fog than the other mesh. The lowest volume of water collected in 60 days is $\left(\mathrm{PE}\right.$ White Sheet plastic $\left.=33.3 \mathrm{~cm}^{3}\right)$. White PE Plastic Sheet is not durable with high wind blow because it is basically use for agricultural purposes. White PE Plastic Sheet usually use on the ground to cover the Earth to prevent weed growth. Therefore, less water droplets can be deposited onto the plastic surfaces. To apply the White PE Plastic Sheet, artificial slit was made to prevent the plastic torn because of wind pressure. For Black Polyolefin Mesh with width $2 \mathrm{~mm}$ weave, the water collected for 60 days are $34.6 \mathrm{~cm}^{3}$ because the mesh were torn from the panel segments for several times because of the wind blow and for HDPE Green Mesh, the volume of water collected are $43.3 \mathrm{~cm}^{3}$.

Table 2. Volume of water collected in 60 days

\begin{tabular}{ccccc}
\hline $\begin{array}{c}\text { Date of } \\
\text { Month }\end{array}$ & White PE & Volume of Water Collected (cm $\left.\mathbf{c}^{3}\right)$ & \\
(February) & Plastic sheet & Mesh (2 mm) & Mesh (1mm) & Green Mesh \\
\hline 1 & N/A & N/A & N/A & N/A \\
2 & N/A & N/A & N/A & N/A \\
3 & N/A & N/A & N/A & N/A \\
4 & N/A & N/A & N/A & N/A \\
5 & N/A & N/A & N/A \\
6 & N/A & N/A & N/A \\
7 & N/A & N/A & N/A & N/A \\
8 & N/A & N/A & N/A \\
\hline
\end{tabular}




\begin{tabular}{|c|c|c|c|c|}
\hline 9 & N/A & N/A & N/A & N/A \\
\hline 10 & 38.6 & 38.6 & 38.6 & 38.6 \\
\hline 11 & 110 & 110 & 110 & 110 \\
\hline 12 & $\mathrm{~N} / \mathrm{A}$ & N/A & N/A & N/A \\
\hline 13 & N/A & N/A & N/A & N/A \\
\hline 14 & N/A & N/A & N/A & N/A \\
\hline 15 & N/A & N/A & N/A & N/A \\
\hline 16 & 154 & N/A & 154 & 295 \\
\hline 17 & N/A & N/A & $\mathrm{N} / \mathrm{A}$ & N/A \\
\hline 18 & $\mathrm{~N} / \mathrm{A}$ & N/A & $\mathrm{N} / \mathrm{A}$ & N/A \\
\hline 19 & $\mathrm{~N} / \mathrm{A}$ & N/A & N/A & N/A \\
\hline 20 & N/A & N/A & N/A & N/A \\
\hline 21 & $\mathrm{~N} / \mathrm{A}$ & N/A & N/A & $\mathrm{N} / \mathrm{A}$ \\
\hline 22 & $\mathrm{~N} / \mathrm{A}$ & N/A & N/A & $\mathrm{N} / \mathrm{A}$ \\
\hline 23 & 120 & 120 & 160 & 165 \\
\hline 24 & $\mathrm{~N} / \mathrm{A}$ & N/A & N/A & N/A \\
\hline 25 & 130 & 38.6 & 110 & 110 \\
\hline 26 & N/A & N/A & N/A & N/A \\
\hline 27 & N/A & N/A & N/A & N/A \\
\hline 28 & N/A & N/A & N/A & N/A \\
\hline 29 & 230 & 110 & 154 & 340 \\
\hline 30 & 230 & 110 & 154 & 340 \\
\hline 31 & $\mathrm{~N} / \mathrm{A}$ & N/A & $\mathrm{N} / \mathrm{A}$ & N/A \\
\hline 32 & $\mathrm{~N} / \mathrm{A}$ & N/A & N/A & N/A \\
\hline 33 & N/A & N/A & N/A & N/A \\
\hline 34 & $\mathrm{~N} / \mathrm{A}$ & N/A & $\mathrm{N} / \mathrm{A}$ & $\mathrm{N} / \mathrm{A}$ \\
\hline 35 & $\mathrm{~N} / \mathrm{A}$ & N/A & $\mathrm{N} / \mathrm{A}$ & $\mathrm{N} / \mathrm{A}$ \\
\hline 36 & $\mathrm{~N} / \mathrm{A}$ & N/A & N/A & N/A \\
\hline 37 & $\mathrm{~N} / \mathrm{A}$ & N/A & $\mathrm{N} / \mathrm{A}$ & N/A \\
\hline
\end{tabular}




\begin{tabular}{|c|c|c|c|c|}
\hline 38 & N/A & N/A & $\mathrm{N} / \mathrm{A}$ & N/A \\
\hline 39 & N/A & N/A & N/A & $\mathrm{N} / \mathrm{A}$ \\
\hline 40 & $\mathrm{~N} / \mathrm{A}$ & N/A & $\mathrm{N} / \mathrm{A}$ & N/A \\
\hline 41 & $\mathrm{~N} / \mathrm{A}$ & N/A & $\mathrm{N} / \mathrm{A}$ & N/A \\
\hline 42 & N/A & N/A & $\mathrm{N} / \mathrm{A}$ & N/A \\
\hline 43 & N/A & N/A & $\mathrm{N} / \mathrm{A}$ & N/A \\
\hline 44 & N/A & N/A & $\mathrm{N} / \mathrm{A}$ & N/A \\
\hline 45 & $\mathrm{~N} / \mathrm{A}$ & N/A & $\mathrm{N} / \mathrm{A}$ & N/A \\
\hline 46 & $\mathrm{~N} / \mathrm{A}$ & N/A & $\mathrm{N} / \mathrm{A}$ & $\mathrm{N} / \mathrm{A}$ \\
\hline 47 & N/A & N/A & $\mathrm{N} / \mathrm{A}$ & $\mathrm{N} / \mathrm{A}$ \\
\hline 48 & 370 & 480 & 700 & 800 \\
\hline 49 & N/A & N/A & $\mathrm{N} / \mathrm{A}$ & N/A \\
\hline 50 & N/A & N/A & $\mathrm{N} / \mathrm{A}$ & $\mathrm{N} / \mathrm{A}$ \\
\hline 51 & N/A & N/A & $\mathrm{N} / \mathrm{A}$ & N/A \\
\hline 52 & $\mathrm{~N} / \mathrm{A}$ & N/A & $\mathrm{N} / \mathrm{A}$ & N/A \\
\hline 53 & $\mathrm{~N} / \mathrm{A}$ & N/A & $\mathrm{N} / \mathrm{A}$ & N/A \\
\hline 54 & 55 & 0 & 0 & 38.6 \\
\hline 55 & N/A & N/A & $\mathrm{N} / \mathrm{A}$ & N/A \\
\hline 56 & 55 & N/A & $\mathrm{N} / \mathrm{A}$ & 38.6 \\
\hline 57 & 250 & N/A & $\mathrm{N} / \mathrm{A}$ & 420 \\
\hline 58 & N/A & N/A & $\mathrm{N} / \mathrm{A}$ & $\mathrm{N} / \mathrm{A}$ \\
\hline 59 & 580 & 920 & 760 & 980 \\
\hline 60 & N/A & N/A & $\mathrm{N} / \mathrm{A}$ & $\mathrm{N} / \mathrm{A}$ \\
\hline
\end{tabular}

$*$ N/A-null data record

Based on Table 2, most of the days in 60 days experimental have no record for volume of water collected unless for several days which are on day 10th, 11th, 16th, 23rd, 29th, 30th, 48th, 54th, 56th, 57th and 59th where the weather is rainy. For null data record is that the water collected is less than $0.1 \mathrm{~cm}^{3}$ or there absence of water in water container due to the hot weather. Figure 2-5 show the volume of water collected for each mesh materials respectively 
to show the differences between the volumes of water collected between 4 mesh materials.

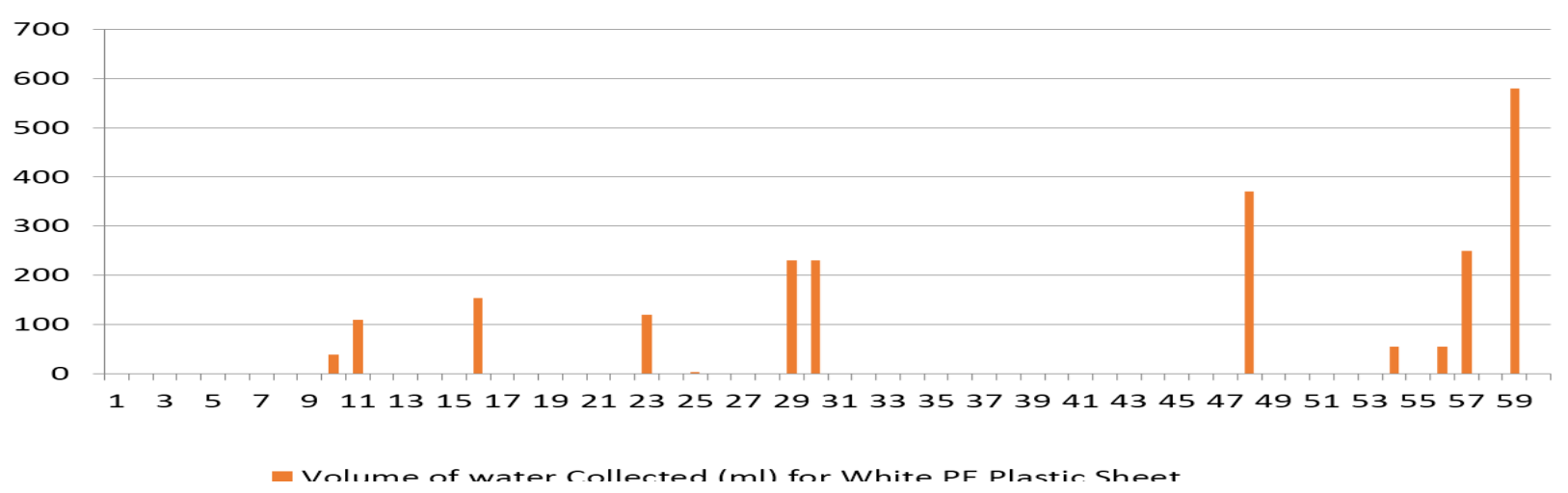

Fig.2. Volume of water collected in 60 days for white PE plastic sheet

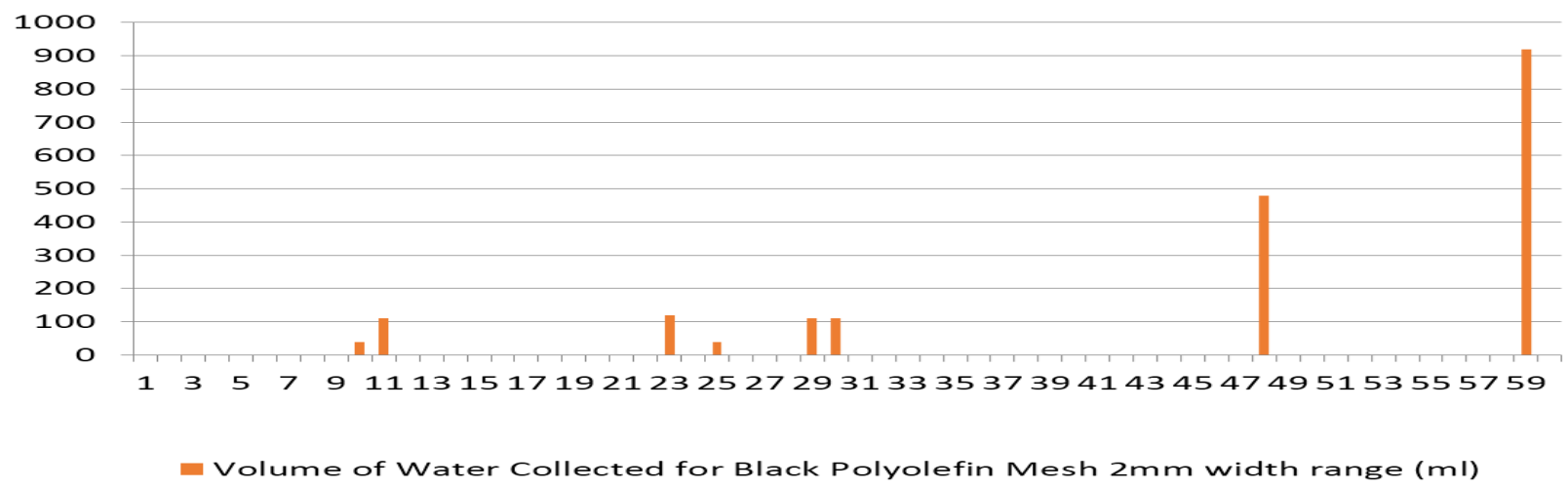

Fig.3. Volume of water collected in 60 days for black Polyolefin mesh ( $2 \mathrm{~mm}$ width range)

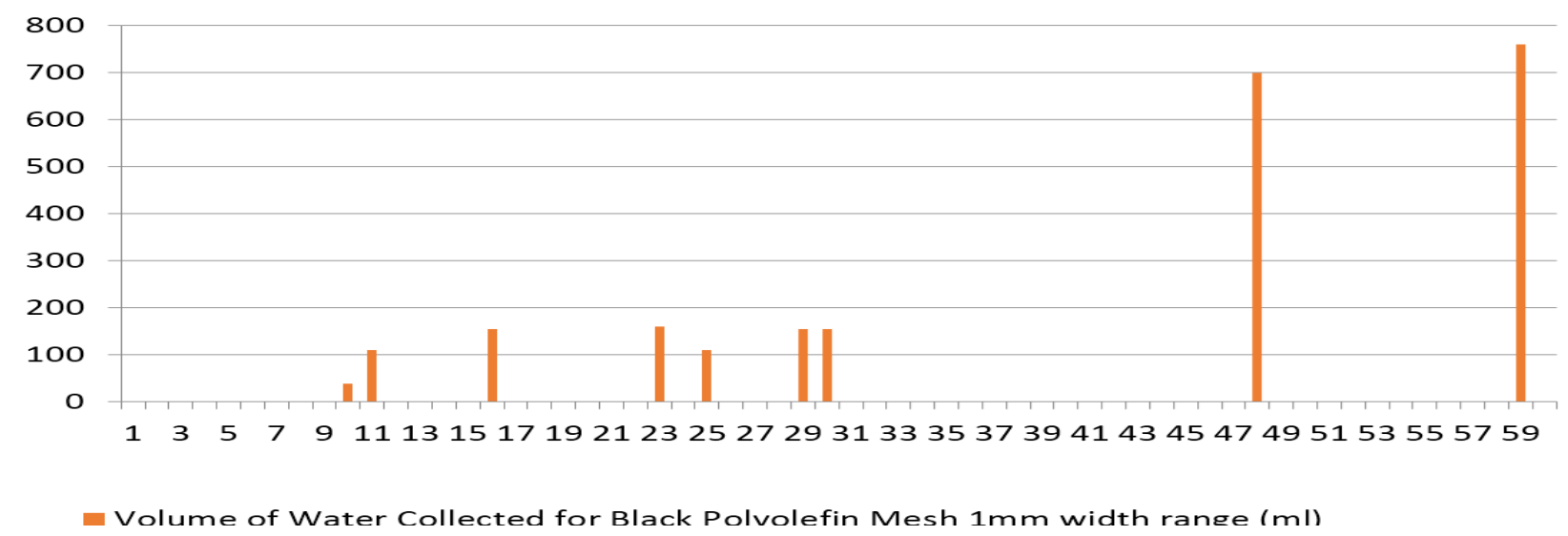

Fig.4. Volume of water collected for black Polyolefin mesh $1 \mathrm{~mm}$ width range (ml) 


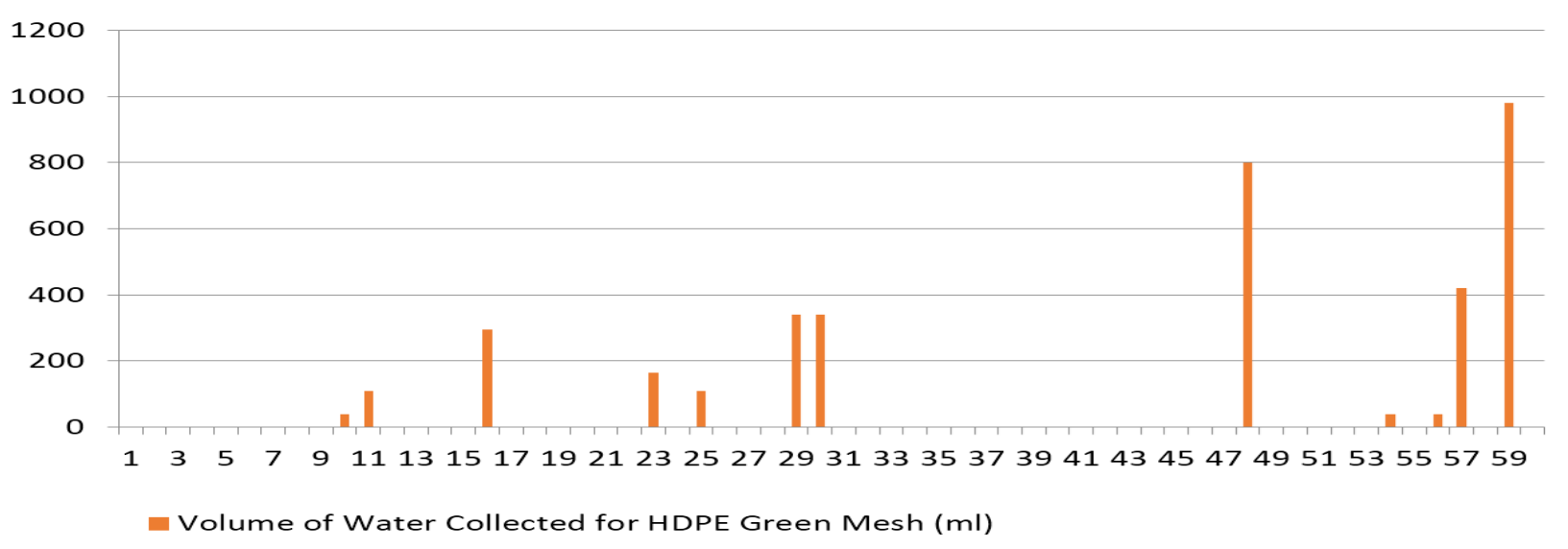

Fig.5. Volume of water collected for HDPE green mesh (ml)

\subsection{One-Way ANOVA Analysis}

Before doing an analysis of variance for feasibility comparison of mesh's material according to its volume of water collected. A descriptive statistical (Table 3) was made by using SPSS software to simplify the task completing the one way ANOVA. 
Table 3. Descriptive statistics for volume of water collected by mesh materials in 60 days

\begin{tabular}{|c|c|c|c|c|c|c|c|c|c|}
\hline \multirow[t]{2}{*}{$\begin{array}{c}\text { Types of } \\
\text { Mesh }\end{array}$} & \multirow[t]{2}{*}{$\begin{array}{c}\text { No } \\
\text { of } \\
\text { Days }\end{array}$} & \multirow[t]{2}{*}{$\mathbf{N}$} & \multirow{2}{*}{$\begin{array}{c}\text { Mean } \\
\text { Water } \\
\text { Collected } \\
\text { (ml) }\end{array}$} & \multirow[t]{2}{*}{$\begin{array}{l}\text { Std. } \\
\text { Dev. }\end{array}$} & \multirow[t]{2}{*}{$\begin{array}{l}\text { Std. } \\
\text { Error }\end{array}$} & \multicolumn{2}{|c|}{$\begin{array}{c}95 \% \\
\text { Confidence } \\
\text { Internal Mean }\end{array}$} & \multirow[t]{2}{*}{ Min } & \multirow[t]{2}{*}{$\operatorname{Max}$} \\
\hline & & & & & & $\mathbf{L B} *$ & $\mathbf{U} \mathbf{P}^{* *}$ & & \\
\hline White PE & 60 & 60 & 36.56 & 102.44 & 13.23 & 10.09 & 63.02 & 0.00 & 580.00 \\
\hline \multicolumn{10}{|l|}{ Plastic } \\
\hline \multicolumn{10}{|l|}{ Sheet } \\
\hline Black & & & 32.12 & 134.58 & 17.37 & -2.65 & 66.88 & 0.00 & 920.00 \\
\hline \multicolumn{10}{|l|}{ Polyolefin } \\
\hline \multicolumn{10}{|l|}{ Mesh } \\
\hline \multicolumn{10}{|l|}{$2 \mathrm{~mm}$} \\
\hline Black & & & 39.01 & 136.46 & 17.62 & 3.76 & 74.26 & 0.00 & 760.00 \\
\hline \multicolumn{10}{|l|}{ Polyolefin } \\
\hline \multicolumn{10}{|l|}{ Mesh } \\
\hline \multicolumn{10}{|l|}{$1 \mathrm{~mm}$} \\
\hline HDPE & & & 61.26 & 180.66 & 23.32 & 14.59 & 107.93 & 0.00 & 980.00 \\
\hline \multicolumn{10}{|l|}{ Green } \\
\hline Mesh & & & & & & & & & \\
\hline
\end{tabular}

*upper boundary

**lower boundary

After creating a descriptive statistical data in Table 3, the analysis was further carry out in Table 4 for one way ANOVA analysis. By using data information in Table 3, ANOVA analysis data was made. 
Table 4. ANOVA analysis

\begin{tabular}{|c|c|c|c|c|c|c|c|}
\hline No & & & $\begin{array}{c}\text { Sum of } \\
\text { Squares (SS) }\end{array}$ & df & $\begin{array}{c}\text { Mean } \\
\text { Square } \\
\left(\boldsymbol{\mu}^{2}\right)\end{array}$ & $\mathbf{F}$ & Sig. \\
\hline \multirow[t]{3}{*}{1} & \multirow{2}{*}{ White PE Plastic } & Between Groups & 619158.944 & 59 & 10494.219 & . & . \\
\hline & & Within Groups & 0.000 & 0 & . & & \\
\hline & Sheet & Total & 619158.944 & 59 & & & \\
\hline \multirow[t]{3}{*}{2} & \multirow{3}{*}{$\begin{array}{c}\text { Black Polyolefin } \\
\text { Mesh } 2 \mathrm{~mm}\end{array}$} & Between Groups & 1068578.256 & 59 & 18111.496 & . & . \\
\hline & & Within Groups & 0.000 & 0 & . & & \\
\hline & & Total & 1068578.256 & 59 & & & \\
\hline \multirow[t]{3}{*}{3} & \multirow{3}{*}{$\begin{array}{c}\text { Black Polyolefin } \\
\text { Mesh } 1 \mathrm{~mm}\end{array}$} & Between Groups & 1098731.154 & 59 & 18622.562 & . & . \\
\hline & & Within Groups & 0.000 & 0 & . & & \\
\hline & & Total & 1098731.154 & 59 & & & \\
\hline \multirow[t]{3}{*}{4} & \multirow{3}{*}{ HDPE Green Mesh } & Between Groups & 1925728.119 & 59 & 32639.460 & . & \\
\hline & & Within Groups & 0.000 & 0 & . & & \\
\hline & & Total & 1925728.119 & 59 & & & \\
\hline
\end{tabular}

$\mu 1=$ mean square for white PE plastic sheet

$\mu 2=$ mean square for black polyolefin mesh with $2 \mathrm{~mm}$ width range

$\mu 3=$ mean square for black polyolefin mesh with $1 \mathrm{~mm}$ width range

$\mu 4=$ mean square for HDPE green mesh

$\mathrm{H}_{0}: \mu 1=\mu 2=\mu 3=\mu 4$

$\mathrm{H}_{1}: \mu 1 \neq \mu 2 \neq \mu 3 \neq \mu 4$

Mean square $\left(\mu^{2}\right)$ is used to test the variability of the test on mesh's material feasibility. According to Table 4, the mean square is different for each mesh's material which means $\mathrm{H}_{0}$ is not accepted while $\mathrm{H}_{1}$ is accepted. Moreover, the $\mathrm{F}$ value is less than 0.0001 which means the terms of feasibility of the material is significant.

\subsection{Multiple Linear Regression Analysis}

The analysis continues with multiple linear regression analysis to find the interrelationship between meteorological effects such as relative humidity, rainfall amount and duration and 
dry bulb temperature. It is important to relate the meteorological effect with the feasibility of materials to prove the applicability of mesh to capture atmospheric water.

ANOVA $^{\mathrm{a}}$

\begin{tabular}{ccccccc}
\hline \multicolumn{1}{l}{ Model } & $\begin{array}{c}\text { Sum of } \\
\text { Squares }\end{array}$ & df & Mean & F & Sig. \\
& & & Square & & \\
\hline & Regression & 8.528 & 4 & 2.132 & 0.542 & $0.706^{\mathrm{b}}$ \\
1 & Residual & 216.518 & 55 & 3.937 & & \\
& Total & 225.046 & 59 & & & \\
\hline
\end{tabular}

a. Dependent Variable: RH (\%)

b. Predictors: (Constant), HDPE_Green_Mesh, Black_Polyolefin_Mesh_2mm, Black_Polyolefin_Mesh_1mm, white_PE_plastic_sheet

ANOVA $^{\mathrm{a}}$

\begin{tabular}{ccccccc}
\hline Model & $\begin{array}{c}\text { Sum of } \\
\text { Squares }\end{array}$ & df & Mean & F & Sig. \\
& & & Square & & \\
\hline & Regression & 3.653 & 4 & 0.913 & 0.069 & $0.991^{\text {b }}$ \\
1 & Residual & 727.197 & 55 & 13.222 & & \\
& Total & 730.850 & 59 & & & \\
\hline
\end{tabular}

a. Dependent Variable: Rainfall_Duration (min)

b. Predictors: (Constant), HDPE_Green_Mesh, Black_Polyolefin_Mesh_2mm, Black_Polyolefin_Mesh_1mm, white_PE_plastic_sheet

\begin{tabular}{|c|c|c|c|c|c|c|}
\hline \multicolumn{7}{|c|}{ ANOVA $^{a}$} \\
\hline & Model & Sum of & df & Mean & $\mathbf{F}$ & Sig. \\
\hline & & Squares & & Square & & \\
\hline \multirow{3}{*}{1} & Regression & .033 & 4 & 0.008 & 0.028 & $0.998^{b}$ \\
\hline & Residual & 16.104 & 55 & 0.293 & & \\
\hline & Total & 16.137 & 59 & & & \\
\hline
\end{tabular}

a. Dependent Variable: Rainfall_Amount (mm)

b. Predictors: (Constant), HDPE_Green_Mesh, Black_Polyolefin_Mesh_2mm, Black_Polyolefin_Mesh_1mm, white_PE_plastic_sheet 


\begin{tabular}{|c|c|c|c|c|c|c|}
\hline \multicolumn{7}{|c|}{ ANOVA $^{a}$} \\
\hline & Model & Sum of & df & Mean & $\mathbf{F}$ & Sig. \\
\hline & & Squares & & Square & & \\
\hline \multirow{3}{*}{1} & Regression & 1.647 & 4 & 0.412 & 0.580 & $0.678^{b}$ \\
\hline & Residual & 39.053 & 55 & 0.710 & & \\
\hline & Total & 40.700 & 59 & & & \\
\hline
\end{tabular}

a. Dependent Variable: Dry_Bulb_Temp

b. Predictors: (Constant), HDPE_Green_Mesh, Black_Polyolefin_Mesh_2mm, Black_Polyolefin_Mesh_1mm, white_PE_plastic_sheet

\section{CONCLUSION}

In a conclusion, the most feasible mesh material for fog harvesting is Black Polyolefin Mesh with $1 \mathrm{~mm}$ width range for weave design where the material can withstand strong wind and has similar properties as wettability surfaces. The hydrophilicity of the mesh materials allowed fog droplets to precipitate onto its surfaces and flow into the water gutter. The width range between the strips of the mesh which is $1 \mathrm{~mm}$ decreases the disappearance of water droplets brought by the wind. Thus, it proves that the impaction of fog particle and surface area of the mesh allows practical fog harvesting.

\section{ACKNOWLEDGEMENTS}

The authors gratefully acknowledge the Ministry of Higher Education, Malaysia and Universiti Malaysia Kelantan in support of this study through the Short-Term Research Grant Scheme (SGJP) R/SGJP/A08.00/00425A/001/2016/000347.

\section{REFERENCES}

[1] Davtalab R, Salamat A, Oji R. Water harvesting from fog and air humidity in the warm and coastal regions in the south of Iran. Irrigation and Drainage, 2013, 62(3):281-288 
[2] Domen J K, Stringfellow W T, Camarillo M K, Gulati S. Fog water as an alternative and sustainable water resource. Clean Technologies and Environmental Policy, 2014, $16(2): 235-249$

[3] Fessehaye M, Abdul-Wahab S A, Savage M J, Kohler T, Gherezghiher T, Hurni H. Fog-water collection for community use. Renewable and Sustainable Energy Reviews, 2014, 29:52-62

[4] Hill A J, Dawson T E, Shelef O, Rachmilevitch S. The role of dew in Negev Desert plants. Oecologia, 2015, 178(2):317-327

[5] Imteaz M A, Al-Hassan G, Shanableh A, Naser J. Development of a mathematical model for the quantification of fog-collection. Resources, Conservation and Recycling, 2011, $57: 10-14$

[6] Klemm O, Schemenauer R S, Lummerich A, Cereceda P, Marzol V, Corell D, van Heerden J, Reinhard D, Gherezghiher T, Olivier J, Osses P. Fog as a fresh-water resource: Overview and perspectives. Ambio, 2012, 41(3):221-234

[7] Mousavi-Baygi M. The implementation of fog water collection systems in Northeast of Iran. International Journal of Pure and Applied Physics, 2008, 4(1):13-21

[8] Park K C, Chhatre S S, Srinivasan S, Cohen R E, McKinley G H. Optimal design of permeable fiber network structures for fog harvesting. Langmuir, 2013, 29(43):13269-13277

[9] Wang Y, Zhang L, Wu J, Hedhili M N, Wang P. A facile strategy for the fabrication of a bioinspired hydrophilic-superhydrophobic patterned surface for highly efficient fog-harvesting. Journal of Materials Chemistry A, 2015, 3(37):18963-18969

[10]Qadir M, Sharma BR, Bruggeman A, Choukr-Allah R, Karajeh F. Non-conventional water resources and opportunities for water augmentation to achieve food security in water scarce countries. Agricultural Water Management, 2007, 87(1):2-22

\section{How to cite this article:}

Isa N H M, Awang N R, Ahmad M I, Rasat M S M, Amin M F M, Rizman Z I. Mesh material feasibility tests for maximum water collection by using white pe plastic sheet, black polyolefin meshes and hdpe green mesh. J. Fundam. Appl. Sci., 2017, 9(3S), 941-954. 